\title{
Hiperinsulinismo endógeno: dois desafios diagnósticos
}

\author{
Endogenous hyperinsulinism: two diagnostic challenges
}

Ana Pires Gonçalves', Fernando Baptista' , Ema Nobre', Isabel do Carmo'

\section{SUMÁRIO}

A hipoglicemia em um adulto aparentemente saudável é um achado raro na prática clínica que exige uma investigação exaustiva da causa. A identificação de glicemia plasmática diminuída associada a concentrações plasmáticas de insulina e peptídeo- $C$ não suprimidos deverá levar à exclusão de causas raras de hipoglicemia, entre elas, doença das células betapancreáticas e hipoglicemia autoimune. Neste artigo, descrevemos dois casos de hipoglicemia associada a hiperinsulinismo endógeno, cujas causas são pouco habituais na prática clínica. A propósito desses casos clínicos revemos aspectos importantes de diagnósticos e tratamento da hipoglicemia no contexto de hiperinsulinismo endógeno. Arq Bras Endocrinol Metab. 2014;58(1):71-5

\section{SUMMARY}

Hypoglycemia in apparently healthy adults is a rare finding in clinical practice requiring a thorough investigation of the cause. During the investigation, identification of hypoglycemia associated with inappropriately high levels of insulin and C-peptide should prompt the exclusion of rare causes of hypoglycemia, including pancreatic islet-cells disease and autoimmune hypoglycemia. In this paper, we describe two cases of hypoglycemia associated with endogenous hyperinsulinism, whose causes are uncommon in clinical practice, and review important aspects of the diagnosis and treatment of hyperinsulinemic hypoglycemia. Arq Bras Endocrinol Metab. 2014;58(1):71-5

${ }^{1}$ Serviço de Endocrinologia, Diabetes e Metabolismo, Hospital de Santa Maria, Centro Hospitalar Lisboa Norte, Lisboa, Portugal

\section{INTRODUÇÃO}

A hipoglicemia é um achado raro na prática clínica, exceto no contexto do tratamento do diabetes melito (DM). Muitas vezes é necessária uma avaliação exaustiva para definir a causa (1). Na investigação, o primeiro passo é a confirmação da tríade de Whipple (sintomas adrenérgicos/neuroglicopênicos, associados à glicemia diminuída, que revertem com administração de glicose).

No adulto, a hipoglicemia está habitualmente associada a um fator facilmente identificável: doença conhecida (cirurgia gástrica, insuficiência hepática e renal graves, sepse, caquexia, tumores de células não beta); medicação habitual (insulina, secretagogos de insulina, quinolonas, pentamidina, betabloqueadores, inibidores da enzima conversora da angiotensina etc.); deficiência dos hormônios contrarreguladores da ação insulínica (por exemplo: cortisol, glucagon e epinefrina).

No adulto aparentemente saudável, deverão ser investigadas causas mais raras. Durante um episódio de hipoglicemia espontânea ou prova de jejum (12 ou
$72 \mathrm{~h}$ ), os seguintes achados sugerem hipoglicemia hiperinsulinêmica endógena: glicemia $<55 \mathrm{mg} / \mathrm{dL}$ no período sintomático, associada à insulinemia $\geq 3 \mathrm{UI} / \mathrm{mL}$ ou $18 \mathrm{pmol} / \mathrm{L}$ (ICMA) (> $6 \mathrm{UI} / \mathrm{mL}$ ou $43 \mathrm{pmol} / \mathrm{L}$, IRMA), peptídeo $C \geq 200 \mathrm{pmol} / \mathrm{L}$ ou $0,60 \mathrm{ng} / \mathrm{mL}$, pró-insulina $\geq 5 \mathrm{pmol} / \mathrm{L}$. Adicionalmente, devem ser doseados os anticorpos anti-insulina e anticorpos antirreceptor de insulina ( 1 ).

Apresentamos dois casos de hipoglicemia com causas pouco habituais na prática clínica.

\section{CASO CLÍNICO 1}

Mulher, 64 anos, internada no nosso serviço para investigação de episódios de hipoglicemia recorrente.

Assintomática até seis meses antes da internação, quando iniciou episódios recorrentes de desorientação e cefaleia, que ocorriam habitualmente após acordar e resolviam com a alimentação. Durante esse período, os episódios foram progressivamente mais frequentes, motivando múltiplas vindas ao Serviço de Urgência (SU). Em uma ocasião, foi observada em período sintomáti- 
co, tendo-se doseado uma glicemia de $32 \mathrm{mg} / \mathrm{dL}$. Os sintomas resolveram com a administração de glicose hipertônica. Decidiu-se pela internação para realização de prova de jejum prolongado.

$\mathrm{Na}$ admissão, confirmou-se o início recente de episódios recorrentes de hipoglicemia em jejum. $\mathrm{O}$ exame objetivo e a avaliação analítica não revelaram alterações.

$\mathrm{Na}$ prova de jejum, 14 horas após o início, a doente apresentou sintomas sugestivos de neuroglicopenia. A avaliação laboratorial confirmou a hipoglicemia (30 $\mathrm{mg} / \mathrm{dL}$ ), pelo que se suspendeu o jejum, com resolução dos sintomas após administração de glicose hipertônica. Na mesma amostra de sangue, a insulinemia, medida por quimioluminescência (Diagnostic Product Corporation), era de $7,7 \mathrm{mmol} / \mathrm{L}(6-27 \mathrm{mmol} / \mathrm{L})$ e o peptídeo-C não se encontrava suprimido.

Repetiu-se o teste de jejum com avaliação da glicemia, insulina, peptídeo-C e proinsulina (Enzyme Immunoassay, IBL [Immunobiological Laboratories, Hamburg]), que mostrou uma elevação clara das concentrações de proinsulina (glicemia - $27 \mathrm{mg} / \mathrm{dL}$, concentração de insulina $-7,8 \mathrm{~mm} / \mathrm{L}$, concentração de peptídeo-C 1,0 ng/mL, concentração de proinsulina $-143 \mathrm{pmol} / \mathrm{L})$.

A ecografia, tomografia computorizada (TC) e ressonância magnética $(\mathrm{RMN})$ não mostraram evidência de lesão focal, pancreática ou em outras localizações. No entanto, a ecografia endoscópica revelou um nódulo de $12 \times 8 \mathrm{~mm}$ na transição da cabeça para o corpo pancreático, acima do canal de Wirsung.

Na peça operatória da resseção do corpo e cauda do pâncreas, encontrou-se um tumor com $14 \mathrm{~mm}$ de maior diâmetro. A análise histológica caracterizou o tumor como bem diferenciado, sem invasão vascular, com imunorreatividade para a insulina (Figura 1), confirmando o diagnóstico de adenoma produtor de proinsulina.

\section{CASO CLÍNICO 2}

Homem, 52 anos, engenheiro, internado para esclarecimento de hipoglicemia.

Referia, desde o ano anterior, episódios de tremor e sudorese geralmente ao fim do dia que melhoravam com a ingestão de alimentos. Teve dois episódios de perda de consciência e em um deles a glicemia era de $23 \mathrm{mg} / \mathrm{dL}$. Foi assistido no SU de um hospital distrital, onde recuperou após injeção de solução de glicose hipertônica.

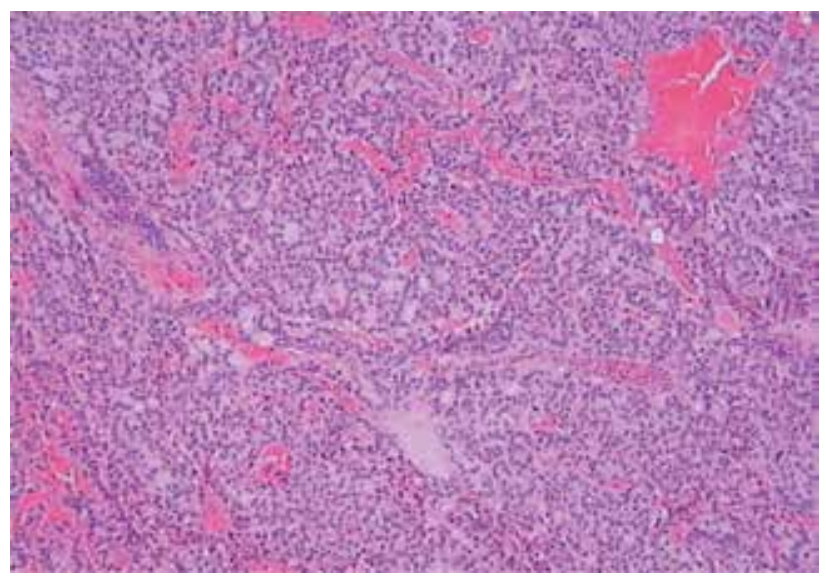

Figura 1. Análise anatomopatológica e imuno-histoquímica. Tumor endócrino bem diferenciado com clara separação entre 0 tecido pancreático normal, sem evidência de invasão vascular, com imunorreatividade positiva para a insulina.

Sem doenças conhecidas, o doente negava sintomas de hipoglicemia em jejum. Nos últimos seis anos, havia ganho $10 \mathrm{~kg}$. Não referia outros sintomas e o exame objetivo era normal.

Internou-se para realização de prova de jejum prolongada cujos resultados, apresentados na figura 2, mostravam elevações francas das concentrações de insulina. O doente manteve-se assintomático e as glicemias foram superiores a $40 \mathrm{mg} / \mathrm{dL}$. As concentrações de peptídeo-C eram baixas, mas dosáveis.

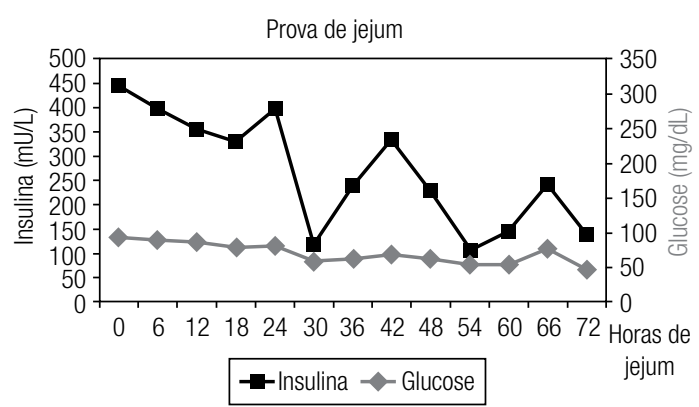

Figura 2. Prova de jejum prolongado. Glicemia e insulinemia durante a prova de 72 horas de jejum.

Não havia alterações da função renal nem hepática. As pesquisas de anticorpos anti-insulina, anticorpos antitireoidianos e antinucleares foram negativas. Fez-se uma prova de tolerância à glucose oral com $75 \mathrm{~g}$ (Figura 3 ), onde se notava a desproporção entre as concentrações de insulina em comparação com a glicemia.

A TC abdominal não mostrou alterações, mas a ecoendoscopia do pâncreas revelou a existência de um pequeno nódulo pancreático. 


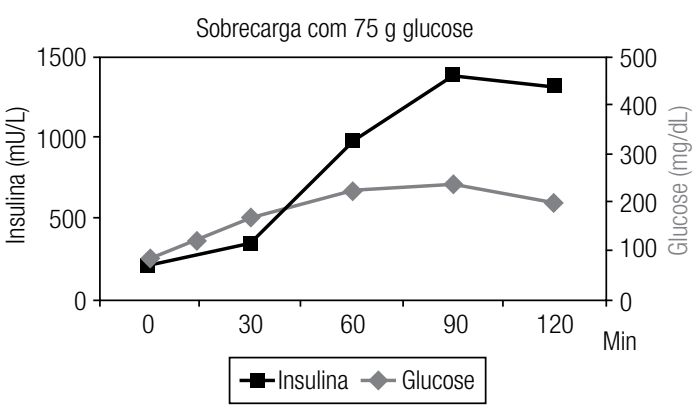

Figura 3. Prova de sobrecarga oral de glicose. Glicemia e insulinemia após sobrecarga oral com $75 \mathrm{~g}$ de glucose.

A eletroforese das proteínas evidenciou um pico monoclonal na região beta, caracterizado por imunoeletroforese como IgG Kappa. A investigação subsequente veio a mostrar que se tratava de um caso de mieloma múltiplo.

Nesse contexto, admitimos que as concentrações elevadas de insulina poderiam ser devidas à presença de um anticorpo fixador de insulina.

Para confirmar essa possibilidade, recolheu-se soro do doente que foi separado em duas amostras. Com a primeira amostra fez-se uma eletroforese (Figura 4A), que confirmou o pico monoclonal. A segunda amostra foi introduzida em uma coluna revestida de anticorpos fixos com alta afinidade para a insulina (Sigma Chemical, St Louis) e, dessa forma, extraíram-se a insulina e o anticorpo a ela ligado. O soro recolhido depois da passagem pela coluna foi submetido à nova eletroforese, verificando-se uma redução do pico monoclonal (Figura 4B). Finalmente, passou-se na coluna um tampão contendo $40 \mathrm{mmol}$ de ácido acético por litro e 1 mol de ácido clorídrico a $\mathrm{pH} 5$, de forma a romper a ligação antígeno-anticorpo. A eletroforese do soro recolhido revelou a existência de um pico monoclonal (Figura 4C).

Concluímos, assim, estarmos perante um caso de hipoglicemia por anticorpo fixador de insulina produzido pelas células do mieloma.

\section{DISCUSSÃO}

Nos casos apresentados, descrevemos a investigação de hipoglicemias recorrentes, documentadas por meio da tríade de Whipple, em adultos aparentemente saudáveis e sem medicação habitual. Em ambos identificou-se, por prova de jejum prolongada, glicemia diminuída associada a concentrações inapropriadamente elevadas de insulina endógena.
A

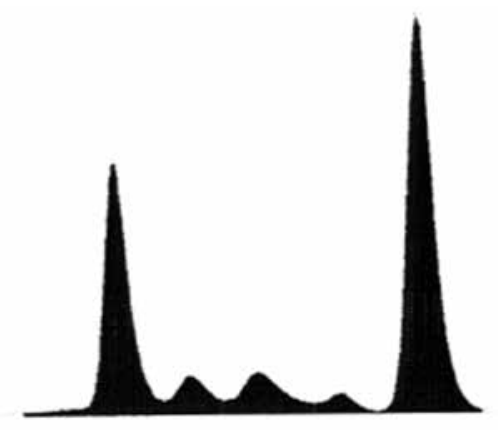

B

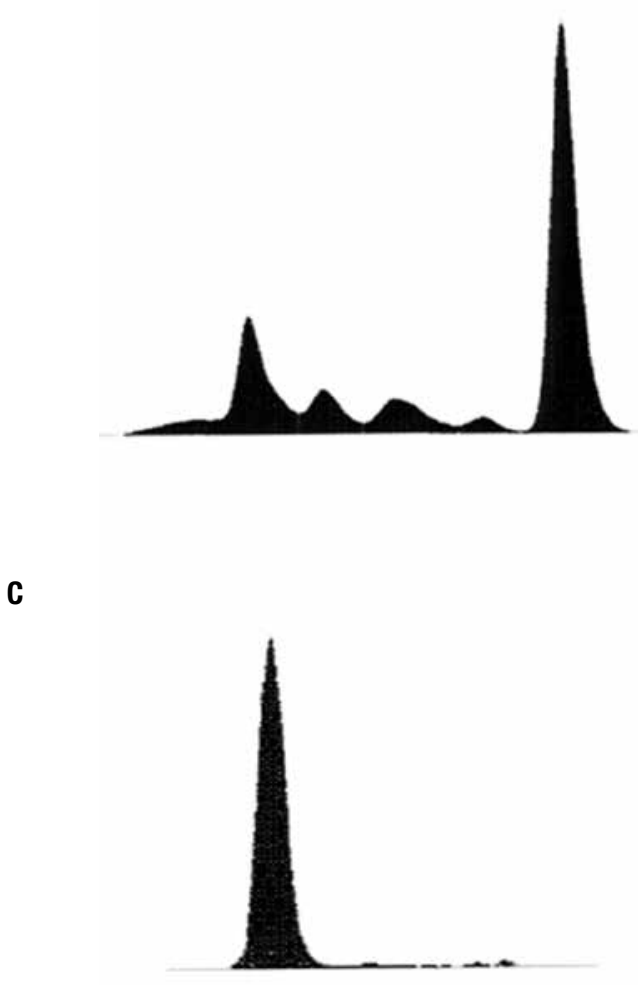

Figura 4. Eletroforese das proteínas do soro. (A) Eletroforese do soro intacto. (B) Eletroforese do soro após extração dos complexos insulinaanticorpo, através de passagem por coluna de alta afinidade para a insulina. (C) Eletroforese do soro obtido por adição de tampão à coluna usada em B.

\section{Discussão do caso 1}

O insulinoma é causa comum de hiperinsulinemia endógena e o tumor neuroendócrino do pâncreas mais frequente. Apresenta uma incidência de 2-4 indivíduos/ milhão/ano e pode ocorrer de forma esporádica ou hereditária no contexto de síndrome de neoplasia endócrina múltipla 1 (MEN l) ou doença de Von Hippel Lindau.

Habitualmente, os insulinomas produzem simultaneamente insulina e proinsulina. Tumores produtores 
apenas de proinsulina, como aquele apresentado no primeiro caso clínico, são raros (2-4).

Embora a proinsulina circulante apresente apenas $20 \%$ de bioatividade comparada com a insulina, durante um período de jejum ou de atividade metabólica elevada, a diminuição progressiva da glicemia associada à falha na supressão de proinsulina resulta em hipoglicemia (2). No caso apresentado, a doente referia sintomas sugestivos de hipoglicemia em período de jejum.

$\mathrm{Na}$ investigação de uma suspeita de insulinoma, é fundamental ter em atenção o tipo de ensaio usado para a dosagem da insulina, uma vez que, enquanto alguns ensaios medem apenas a molécula intacta de insulina, outros medem simultaneamente a proinsulina e peptídeo-C (40-80\% de reação cruzada entre a proinsulina e insulina) (2-4).

Atualmente, são mais frequentemente usados ensaios imunorradiométricos (IRMA) ou imunoquimioluminescentes (ICMA) que não apresentam reação cruzada com a proinsulina. Esse foi o método utilizado no caso descrito, o que, associado à não dosagem inicial da proinsulina, conduziu ao atraso no diagnóstico. No entanto, o fato de o doente apresentar hipoglicemia associada a concentrações fisiológicas de insulina levou à repetição da prova de jejum com perfil laboratorial mais completo, que permitiu identificar um adenoma produtor apenas de proinsulina. Outros aspectos a considerar na interpretação da insulinemia são: atraso no processamento das amostras (a insulina apresenta uma meia-vida curta, de aproximadamente 4 minutos) e hemólise na amostra de sangue, que podem se associar a alterações artefatuais na dosagem da insulina (3).

Assim, na investigação de hiperinsulinemia endógena, é fundamental pedir especificamente a dosagem da proinsulina, caso contrário há o risco de atrasar ou falhar o diagnóstico.

\section{Discussão do caso 2}

No segundo caso, a investigação permitiu identificar hipoglicemia autoimune associada à produção de anticorpos monoclonais por mieloma múltiplo.

A síndrome autoimune da insulina é uma causa rara de hipoglicemia nos países ocidentais e existem apenas dois casos relatados em Portugal (5-7).

Surge habitualmente em indivíduos de meia-idade, tal como no caso apresentado, e não existe predileção de gênero (2). A hipoglicemia é tipicamente pós-prandial, embora haja casos descritos de hipoglicemia em jejum e precipitada por exercício (2). No caso descrito, o doente referia sintomas ao final do dia, sem relação com as refeições.

São fatores predisponentes: o antígeno leucocitário humano (HLA) DR4 (6-9), o que explica a maior prevalência na população japonesa; a existência de outro tipo de autoimunidade, em particular a doença de Graves, mas também o lúpus eritematoso sistêmico, artrite reumatoide, polimiosite e anticorpos anti-hipófise; a exposição a fármacos, em particular fármacos contendo grupo sulfridil (metimazol, captopril, imipenem, penicilina e betalactâmicos), insulina, hidrazalina, procainamida, isoniazida, interferon-alfa. $(8,10,11)$. No caso descrito, não havia evidência de outro tipo de autoimunidade nem exposição a fármacos. $\mathrm{O}$ doente não foi caracterizado em relação à existência de HLA de risco.

Apesar de o doente apresentar dosagens de anticorpos anti-insulina e antirreceptor de insulina negativos pelo método de ELISA, alguns dados laboratoriais permitiam suspeitar de causa autoimune (8):

- Concentrações de insulina que variavam entre 150 e $400 \mathrm{mU} / \mathrm{L}$, com peptídeo-C não suprimido. Uma insulinemia superior a $100 \mathrm{uU} /$ $\mathrm{mL}$, com níveis de peptídeo-C não suprimidos, é muito sugestiva de causa autoimune (no insulinoma raramente a concentração de insulina excede esse valor e, no caso de administração de insulina exógena, o peptídeo-C está suprimido) $(6,8,9)$.

- Na prova de administração de $75 \mathrm{~g}$ de glicose oral, verificava-se uma desproporção grande entre a glicemia e a insulinemia.

Deve mencionar-se, no entanto, que atualmente se considera mais adequada a realização de um teste de refeição padrão, em substituição da prova de tolerância oral à glicose. Em um teste de refeição padrão, os indivíduos com hipoglicemia autoimune apresentam hiperglicemia inicial, seguida de hipoglicemia e cinética da insulina alterada, caracterizada por pico prolongado e atraso no declínio da insulinemia total e/ou livre séricas em relação ao peptídeo-C.

A eletroforese de proteínas foi o elemento chave que levou à identificação de mieloma múltiplo e permitiu suspeitar dessa causa rara de hipoglicemia.

$\mathrm{O}$ doseamento falsamente negativo de anticorpos anti-insulina por ELISA poderá ter resultado de a existência de complexos insulina - anticorpo anti-insulina endógeno - ter dificultado a ligação ao anticorpo sinalizador. 
A síndrome autoimune da insulina, muito raramente, associa-se a gamopatias monoclonais (gamopatia monoclonal benigna e mieloma múltiplo) $(9,12)$.

Enquanto na síndrome autoimune da insulina, habitualmente, os anticorpos são imunoglobulinas G policlonais, com cadeias leves Kappa e Lambda (2), nas discrasias de células plasmocitárias os anticorpos são monoclonais, habitualmente do tipo IgG (existe apenas um relato de hipoglicemia secundária a mieloma produtor de IgA) (9). Em ambos os casos, os anticorpos apresentam elevada capacidade e baixa afinidade $(2,13)$. No caso descrito, o doente apresentava um mieloma múltiplo produtor de $\mathrm{IgG}$ Kappa que não tivemos oportunidade de caracterizar em termos de capacidade e afinidade.

Na investigação do mecanismo subjacente à hipoglicemia autoimune, encontramos várias hipóteses.

Estudos com insulina radiomarcada favorecem a hipótese que propõe um mecanismo mediado pela ligação e dissociação dos anticorpos sem relação com a glicemia. Nesses indivíduos, após uma refeição a concentração de insulina livre aumenta em resposta à glicemia, com ligação a anticorpos de baixa afinidade e elevada capacidade $(8,14,15)$. Disso resultam hiperglicemia inicial e secreção adicional de insulina. À medida que a glicemia diminui, a secreção de insulina é suprimida e a concentração total de insulina diminui. Uma vez que os anticorpos anti-insulina têm baixa afinidade, quando a insulinemia diminui, são libertados, resultando em concentração inapropriadamente elevada de insulina livre relativamente à glicemia.

Outras hipóteses propõem ligação cruzada entre insulina e complexo receptor - insulina mediada pelo anticorpo com prolongamento e potenciação do efeito da insulina; ativação direta dos receptores de insulina; e estimulação direta da secreção pancreática de insulina $(8,14,15)$.

\section{CONCLUSÃO}

Em conclusão, a hiperinsulinemia endógena é um desafio diagnóstico. Na investigação, é fundamental dosar especificamente a proinsulina, uma vez que, em casos raros, a hipoglicemia pode resultar da produção autônoma dessa molécula e consequente falha da supressão durante um período de diminuição rápida ou prolongada da glicemia. Da mesma maneira, a hipoglicemia au- toimune, embora seja uma causa rara, deve ser sempre considerada no diagnóstico diferencial dessa síndrome, uma vez que o diagnóstico correto pode evitar intervenções cirúrgicas desnecessárias.

Declaração: os autores declaram não haver conflitos de interesse científico neste estudo.

\section{REFERÊNCIAS}

1. Cryer PE, Axelrod L, Grossman AB, Heller SR, Montori VM, Seaquist $E R$, et al. Evaluation and management of adult hypoglycemic disorders: an endocrine society clinical practice guideline. J Clin Endocrinol Metab. 2009;94:709-28.

2. Arioglu E, Gottlieb NA, Koch CA, Doppman JL, Grey NJ, Gorden P. Natural history of a proinsuline-secreting insulinoma: from symptomatic hypoglycemia to clinical diabetes. J Clin Endocrinol Metab. 2000;85(10):3628-30.

3. Coelho C, Druce M, Grossman AB. Diagnosis of insulinoma in a patient with hypoglycemia without obvious hyperinsulinemia. Nat Rev Endocrinol. 2009;5(11):628-31.

4. Fadini GP, Maran A, Valerio A, Meduri F, Pelizzo M, Miotto D, et al. Hypoglycemic syndrome in a patient with proinsulin-only secreting pancreatic adenoma (proinsulinoma). Case Rep Med. 2011;2011:930904.

5. Cavaco B, Uchigata $Y$, Porto T, Amparo-Santos M, Sobrinho L, Leite V. Hypoglycaemia due to insulin autoimmune syndrome: report of two cases with characterization of HLA alleles and insulin autoantibodies. Eur J Endocrinol. 2001;145:311-6.

6. Yaturu S, DePrisco C, Lurie A. Severe autoimmune hypoglycemia with insulin antibodies necessitating plasmapheresis. Endocr Pract. 2004;10(1):49-54.

7. Ma W, Won J, Tang K, Lin H. Severe hypoglycemic coma due to insulin autoimmune syndrome. J Chin Med Assoc. 2005;68 (2):82-6.

8. Redmon JB, Nuttal F. Autoimmune hypoglycemia. Endocrinol Metab Clin North Am. 1999;28(3):603-18.

9. Halsall DJ, Mangri M, Soos M, Fahie-Wilson MN, Wark G, Mainwaring-BurtonO'Rahilly. Hypoglycemia due to an insulin binding antibody in a patient with IgA-kappa myeloma. J Clin Endocrinol Metab. 2007;92(6):2013-6.

10. Hirata $Y$, Tominaga $M$, Ito Jl, Noguchi A. Spontaneous hypoglycemia with insulin autoimmunity in Graves' disease. Ann Intern Med. 1974;81:214-8.

11. Moreira RO, Lima GA, Peixoto PC, Farias ML, Vaisman M. Insulin autoimmune syndrome: case report. Sao Paulo Med J. 2004;122(4):178-80.

12. Redmon B, Pyzdrowski K, Elson M, Kay N, Dalmasso A, Nuttall F. Brief report: hypoglycemia due to a monoclonal insulin-binding antibody in multiple myeloma. N Engl J Med. 1992;326(15):994-8.

13. Vezzosi D, Bennet A, Fauvel J, Caron P. Insulin, peptide-C and proinsulin for the biochemical diagnosis of hypoglycemia related to endogenous hyperinsulinism. Eur J Endocrinol. 2007;157(1):75-83.

14. Fineberg S, Galloway J, Fineberg N, Rathbun M, Hufferd S. Immunogenicity of recombinant DNA human insulin. Diabetologia. 1983;25:465-9.

15. Ma WY, Won JG, Tang KT, Lin HD. Severe hypoglycemic coma due to insulin autoimmune syndrome. J Chin Med Assoc. 2005;68(2):82-6. 